\title{
非导电工程陶瓷高能量电容单脉冲放电高效 加工试验研究
}

\author{
纪仁杰*，刘永红，张彦振，张海峰，李小朋，董欣
}

(1) 中国石油大学(华东)机电工程学院, 东营 257061

*E-mail: jirenjie202@yahoo.cn, liuyhupc@126.com

收稿日期: 2010-01-31; 接受日期: 2011-01-12

国家自然科学基金(批准号: 50675225)和国家科技部科技人员服务企业行动项目(批准号: 2009GJC60047)资助项目

\begin{abstract}
摘要针对传统加工方法在加工非导电工程陶瓷时存在加工效率低、成本高以及加工表面 质量差等缺点, 本文提出了非导电工程陶瓷高能量电容高效电火花加工新方法, 并进行了单 脉冲放电试验研究, 结果表明, 该方法采用高电压大电容以及较高的放电能量, 能够较大地 提高材料去除效率, 单次脉冲放电陶瓷去除量可达 $17.63 \mathrm{~mm}^{3}$. 对加工极性、峰值电压、电容、 限流电阻、工具电极进给方式、工具电极截面积以及辅助电极厚度等参数对陶瓷蚀除坑体积、 工具电极损耗以及辅助电极损耗等性能的影响进行了试验研究与理论分析, 得到了相应的规 律关系. 采用扫描电子显微镜对单脉冲放电坑的微观形貌进行了观测. 结果表明: 放电坑表 面呈溅射状，陶瓷主要以剥落方式去除，放电通道中心区域部分材料以熔化蒸发方式去除， 且材料去除效果随着加工参数的增大而增强.
\end{abstract}

关键词

电火花

非导电工程陶瓷

单脉冲

高能量电容
非导电工程陶瓷因具有高强度、高硬度、高耐磨 性、高热稳定性、高化学稳定性等优良性能, 已越来 越广泛的应用于石油、地质、电子、机械、治金、化 工、航空航天等行业和领域中, 并带来了巨大的社会 和经济效益 ${ }^{[1 \sim 3]}$. 但非导电工程陶瓷的高硬度、高脆 性以及绝缘性给其加工带来了极大的困难 ${ }^{[4]}$.

使用金刚石砂轮的磨削加工是目前最常用的陶 瓷加工方法, 该方法需要高刚度的磨床和昂贵的金 刚石砂轮, 加工成本高, 生产效率低, 并且加工后的 陶瓷表面和亚表面会产生多种类型的损伤, 从而影 响工件的最终使用性能 ${ }^{[5,6]}$; 超声波加工适于加工各 种工程陶瓷, 加工过程中的切削力和切削热很小, 不 会引起工件变形和烧伤, 但超声波加工效率低, 工具
损耗较为严重 ${ }^{[7,8]}$; 激光加工主要适用于陶瓷的切 割、打孔和刻蚀, 其设备昂贵、加工区存在明显的热 影响层, 易在陶瓷加工表面上形成微裂纹, 降低零件 的使用性能 ${ }^{[9,10]}$. 电火花加工是一种非接触加工, 可 以用软的工具加工硬的工件、且加工中没有切削力的 影响, 避免了机械应力导致的加工工件质量下降, 因 此它是加工工程陶瓷的一种较理想的方法, 但是传 统的电火花加工方法只能加工导电的工程陶瓷, 非 导电工程陶瓷的电火花加工技术研究是当今特种加 工领域的一个研究热点 ${ }^{[1113]}$.

非导电工程陶瓷的电解电火花复合加工技术利 用电解液中的火花放电作用进行加工, 加工过程中 需要消耗大量的电能, 存在加工精度差、效率低、易

英文版发表信息: Ji R J, Liu Y H, Zhang Y Z, et al. An experimental research on single discharge machining of insulating ceramics efficiently with high energy capacitor. Sci China Tech Sci, 2011, 54: 1537-1545, doi: 10.1007/s11431-011-4327-y 
锈蚀机床、易污染环境等缺陷 ${ }^{[14 \sim 16]}$. 辅助电极电火花 加工方法是利用工具电极与放置在非导电陶瓷上的 金属辅助电极间的火花放电作用以及火花放电时的 碳化导电作用实现对非导电陶瓷电火花加工的，该 方法加工效率低, 仅能用于小孔加工, 且加工孔的深 度较浅 ${ }^{[17,18]}$. 非导电工程陶瓷的机械电解电火花复 合磨削(MEEC)方法与单纯的机械磨削相比具有生产 率高、加工质量好和成本低等优点, 但由于在加工过 程中要消耗大量的电解能来形成电解液中火花放电 时所需要的绝缘气体相, 削弱了火花放电的蚀除作 用, 且加工过程中对环境有污染, 易锈蚀机床, 因此 未能在实际生产中得到应用 ${ }^{[19]}$.

Liu 等人 ${ }^{[20,21]}$ 研究开发出了非导电工程陶瓷双 电极同步伺服电火花铣削加工技术，该技术利用旋 转的铣削轮电极和同步伺服进给的辅助薄片电极之 间放电产生的瞬时高温、高压作用来蚀除陶瓷材料, 在加工非导电的 $\mathrm{Al}_{2} \mathrm{O}_{3}$ 陶瓷时效率可达 $133 \mathrm{~mm}^{3} \mathrm{~min}^{-1}$, 具有加工效率高、成本低和对环境无污染等优点. 为 了进一步提高非导电工程陶瓷的加工效率, 本文提 出了高能量电容高效电火花加工新方法, 并针对该 方法设计出了单脉冲放电装置, 进行了非导电工程 陶瓷的单脉冲放电试验研究. 结果表明, 由于在加工 过程中采用高电压大电容以及较高的放电能量, 能 够较大地提高材料去除效率, 单次脉冲放电的陶瓷 去除量可达 $17.63 \mathrm{~mm}^{3}$.

为了研究该方法加工非导电工程陶瓷的基本工 艺规律, 掌握其工艺特点和技术关键, 本文对加工极 性、峰值电压、电容、限流电阻、工具电极进给方式、 工具电极截面积以及辅助电极厚度等参数对陶瓷蚀 除坑体积、工具电极损耗以及辅助电极损耗等性能的 影响进行了试验研究与理论分析, 总结出了相应的 规律关系, 为非导电工程陶瓷高能量电容高效电火 花加工技术的应用提供了理论支持和工艺指导.

\section{1 试验原理和试验条件}

\section{1 试验原理}

图 1 为高能量电容单脉冲放电加工非导电工程 陶瓷的示意图. 由图 1 可以看出, 该电路主要包括充 电电路和放电电路两个部分, 当开关 $\mathrm{S}_{1}$ 闭合, $\mathrm{S}_{2}$ 断开 时, 电源给电容充电, 电容充电结束后, 断开 $S_{1}$, 闭 合 $S_{2}$, 启动伺服电机, 使工具电极逐渐靠近辅助电
极, 通过电压检测电路对间隙状态进行检测, 随着极 间距离的缩小, 电场强度逐渐增大, 当电压检测电路 检测到极间被击穿时, 反馈信号控制伺服电机停止 进给, 电容中存储的能量通过工具电极瞬时释放到 辅助电极上, 由于辅助电极很薄并且紧贴工件表面, 因此可以认为火花放电能量直接作用于非导电工程 陶瓷表面, 由火花放电产生的瞬时高温、高压作用来 蚀除陶瓷材料. 由于在加工过程中采用高电压大电 容以及较高的放电能量, 能够较大地提高材料去除 效率. 图 2 是空气中非导电氧化铝陶瓷单脉冲放电时 的照片.

\section{2 试验条件}

试验中所用的工件为非导电 $\mathrm{Al}_{2} \mathrm{O}_{3}$ 陶瓷板, 工具 电极材料为紫铜棒, 辅助电极材料为紫铜片. 用电子 天平(Sartorius BS224S)分别对加工前后陶瓷板、工具 电极以及辅助电极的质量进行测量, 每个数据测量 5 次, 求取平均值作为测量结果, 计算得到陶瓷、工具 电极以及辅助电极的单脉冲放电去除量. 工具电极 损耗(TWR)和辅助电极损耗(AEWR)的计算方法分别 如 (1) 和 (2) 式所示. 用扫描电子显微镜 (SEM FEI.QUANTA 200)对陶瓷单脉冲放电坑形貌进行观 测, 在以下的各试验中, 未列出的加工参数取表 1 所 示的值.

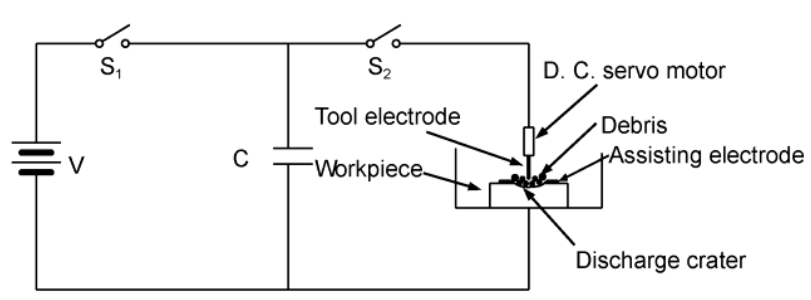

图 1 高能量电容单脉冲放电加工非导电工程陶瓷原理图

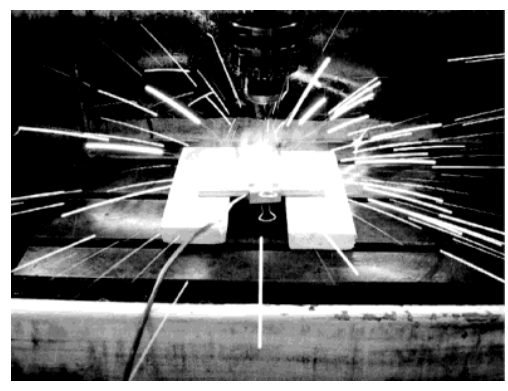

图 2 非导电氧化铝陶瓷高能量电容单脉冲放电照片 
表 1 试验加工参数

\begin{tabular}{cc}
\hline 试验参数 & 数值 \\
\hline 加工极性 & 工具电极 $(-)$ \\
峰值电压 $(\mathrm{V})$ & 300 \\
电容 $(\mu \mathrm{F})$ & 20000 \\
限流电阻 $(\Omega)$ & 0 \\
工具电极截面积 $\left(\mathrm{mm}^{2}\right)$ & 2 \\
辅助电极厚度 $(\mathrm{mm})$ & 0.05 \\
工具电极进给方式 & 垂直 \\
加工介质 & 空气 \\
& \\
& \\
$\operatorname{TWR}=\frac{\rho_{1}\left(m_{2}-m_{5}\right)}{\rho_{2}\left(m_{1}-m_{4}\right)} \times 100 \%$, & \\
$\operatorname{AEWR}=\frac{\rho_{1}\left(m_{3}-m_{6}\right)}{\rho_{3}\left(m_{1}-m_{4}\right)} \times 100 \%$,
\end{tabular}

其中 $m_{1}, m_{2}, m_{3}$ 分别为加工前陶瓷、工具电极和辅助 电极的质量; $m_{4}, m_{5}, m_{6}$ 分别为加工后陶瓷、工具电极 和辅助电极的质量; $\rho_{1}, \rho_{2}, \rho_{3}$ 分别为陶瓷、工具电极 和辅助电极的密度.

\section{2 试验结果和讨论}

\section{1 极性对加工效果的影响}

加工极性对非导电工程陶瓷高能量电容单脉冲 放电加工效果的影响关系如图 3 所示. 由图 3 可知, 在其他条件相同的情况下，负极性工具电极加工时 的陶瓷去除量是正极性工具电极加工时的 1.1 1.7 倍, 正极性工具电极加工时的工具电极损耗是负极性工 具电极加工时的 3.3 4.3 倍, 正极性工具电极加工时 的辅助电极损耗是负极性工具电极加工时的 1.8 4.6 倍. 根据火花放电的极性效应可知, 当工具电极接电 源正极时工件材料主要受正离子的轰击, 当工具电 极接电源负极时工件材料主要受电子的轰击 ${ }^{[22]}$. 本 试验中, 当工具电极和辅助电极之间的间隙达到放 电间隙的尺度时, 产生火花放电, 电容中储存的能量 瞬时释放到放电间隙中, 放电时间非常短. 由于电子 的质量和惯性远小于正离子的质量和惯性, 因此在 很短的放电时间内电子能够被加速, 电子的轰击作 用远大于正离子的轰击作用, 所以当工具电极接电 源负极时陶瓷去除量较高, 工具电极损耗较低. 当工 具电极接电源负极时辅助电极损耗较小, 这可以解 释为：当工具电极接电源负极时, 陶瓷的去除量较 高, 试验中可以观察到部分熔化飞溅出的陶瓷材料
黏附到辅助电极表面上, 减缓了辅助电极的损耗, 并 对辅助电极的损耗进行一定的补偿, 而当工具电极 接电源正极时, 陶瓷去除量较小, 在辅助电极表面没 有陶瓷材料的黏附，因此当工具电极接电源负极时 辅助电极损耗较小. 由上述分析可以看出, 负极性工 具电极加工时的加工效果较好.
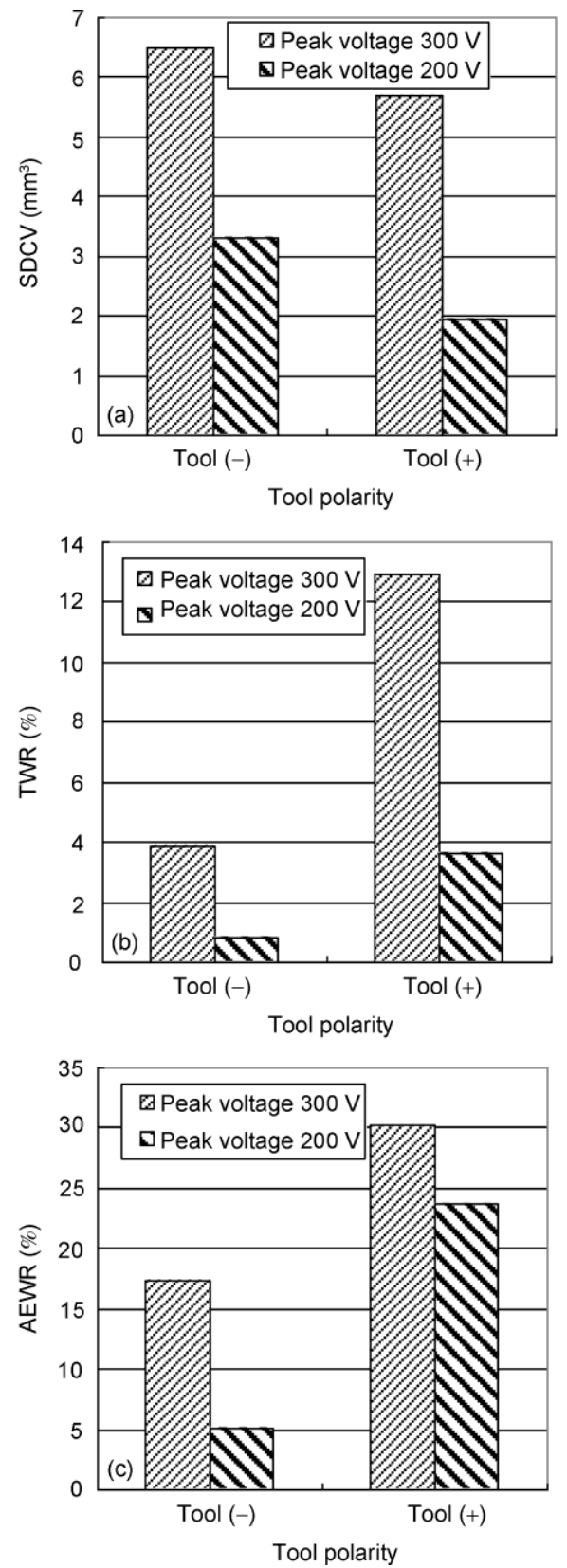

图 3 加工极性对加工效果的影响

（a) 极性对陶瓷去除量的影响; (b) 极性对工具电极损耗的影响; (c) 极性对辅助电极损耗的影响 


\section{2 峰值电压对加工效果的影响}

图 4 为在其他条件相同的情况下, 得到的峰值电 压与陶瓷去除量、工具电极损耗以及辅助电极损耗的 关系曲线. 由图 4 可以看出, 随着峰值电压的增加, 单次脉冲放电的陶瓷去除量、工具电极损耗以及辅助 电极损耗均增加. 这是因为随着峰值电压的增加, 电 容中存储的能量增加, 在放电过程中传递给电极和 工件的能量增加，因此陶瓷去除量、工具电极损耗以 及辅助电极损耗增加. 由图 4 还可以看出, 当峰值电
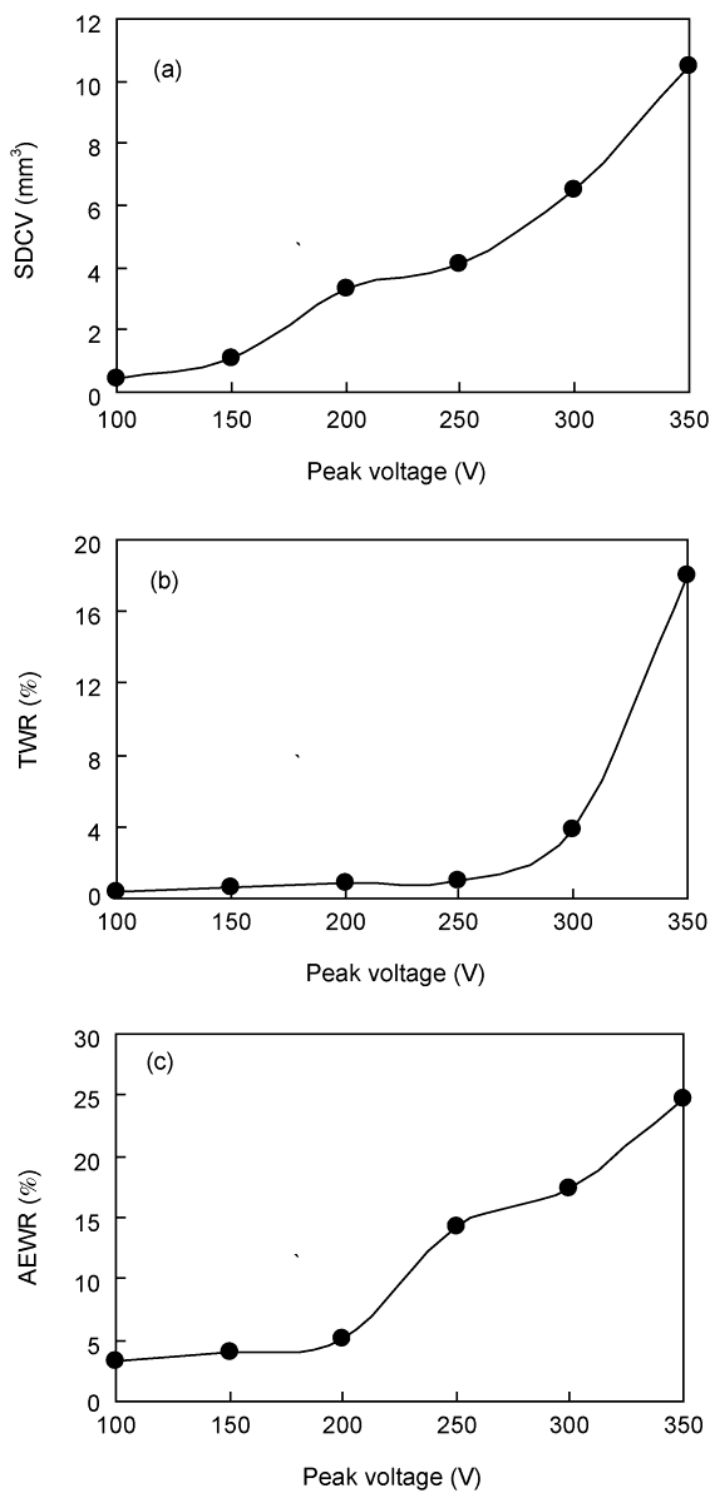

图 4 峰值电压对加工效果的影响

(a) 峰值电压对陶瓷去除量的影响; (b) 峰值电压对工具电极损耗的 影响; (c) 峰值电压对辅助电极损耗的影响
压小于 $300 \mathrm{~V}$ 时, 工具电极损耗随着峰值电压的增加 变化不大，当峰值电压从 $300 \mathrm{~V}$ 增加到 $350 \mathrm{~V}$ 时，工 具电极损耗迅速增加. 这可以解释为: 当峰值电压小 于 $300 \mathrm{~V}$ 时, 随着峰值电压的增加, 单个脉冲能量的 增大使得工具电极单次放电时的蚀除量增加, 但是 陶瓷去除量也增加，两者综合作用使得工具电极损 耗变化不大, 但是当峰值电压从 $300 \mathrm{~V}$ 增加到 $350 \mathrm{~V}$ 时, 放电电流密度迅速增大, 放电通道中的能量密度 和放电爆炸力迅速增加, 工具电极材料从熔化去除 转变为剥落去除, 大大增加了工具电极的去除量, 因 此工具电极损耗迅速增加.

\section{3 电容对加工效果的影响}

电容对加工效果的影响规律如图 5 所示. 由图 5 可知, 在其他条件相同的情况下，随着电容容量的增 加, 单次脉冲放电的陶瓷去除量、工具电极损耗以及 辅助电极损耗均增加. 这是因为随着电容容量的增 加, 电容中存储的能量增加, 在放电过程中传递给电 极和工件的能量增加，因此陶瓷去除量、工具电极损 耗以及辅助电极损耗均增加. 由图 5 还可以看出, 当 电容小于 $20000 \mu \mathrm{F}$ 时, 工具电极损耗随着电容的增 加变化不大, 当电容从 $20000 \mu \mathrm{F}$ 增加到 $25000 \mu \mathrm{F}$ 时, 工具电极损耗迅速增加. 这是因为, 当电容小于 $20000 \mu \mathrm{F}$ 时, 随着电容容量的增加, 电容中存储的能 量增加, 工具电极在放电过程中的蚀除量增加, 但是 陶瓷去除量也增加，两者综合作用使得工具电极损 耗变化不大, 但是当电容从 $20000 \mu \mathrm{F}$ 增加到 25000 $\mu \mathrm{F}$ 时, 电容中存储能量的增加使得放电电流密度和 放电爆炸力迅速增大, 工具电极材料从熔化去除转 变为剥落去除, 大大增加了工具电极的去除量, 因此 工具电极损耗迅速增加.

\section{4 限流电阻对加工效果的影响}

通过在放电电容与放电回路间串联限流电阻来 改变峰值电流，进而改变单次放电时释放到放电间 隙中的能量, 限流电阻对加工效果的影响关系如图 6 所示. 由图 6 可知, 在其他条件相同的情况下，随着 限流电阻的增加, 陶瓷去除量、辅助电极损耗和工具 电极损耗均减小, 这是因为随着限流电阻的增加, 峰 值电流减小, 放电过程中传递给电极和工件的能量 减小，因此陶瓷去除量和电极损耗均减小。由图 6 还 可以看出, 当限流电阻大于 $4 \Omega$ 时, 工具电极损耗为 

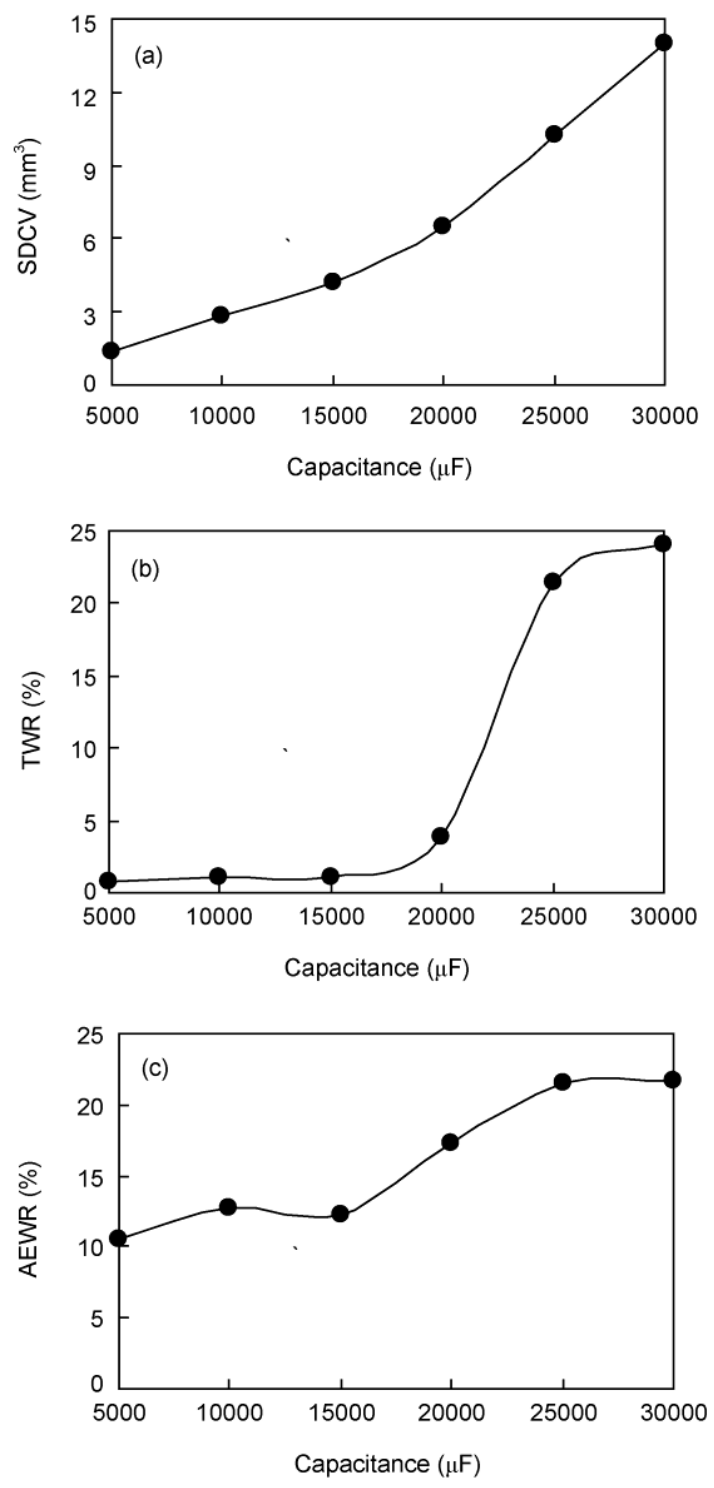

图 5 电容对加工效果的影响

(a) 电容对陶瓷去除量的影响; (b) 电容对工具电极损耗的影响;

(c) 电容对辅助电极损耗的影响

负值. 这是因为当限流电阻大于 $4 \Omega$ 时, 放电能量和 放电爆炸力较小, 放电过程中产生的部分碎屑黏附 到工具电极表面上, 超过了工具电极在放电中的消 耗，因此工具电极损耗为负值.

\section{5 工具电极移动方式对加工效果的影响}

不同工具电极移动方式如图 7 所示, 当工具电 极水平移动时，伺服电机控制工具电极做水平方向 的伺服运动. 图 8 为工具电极移动方式对加工效果
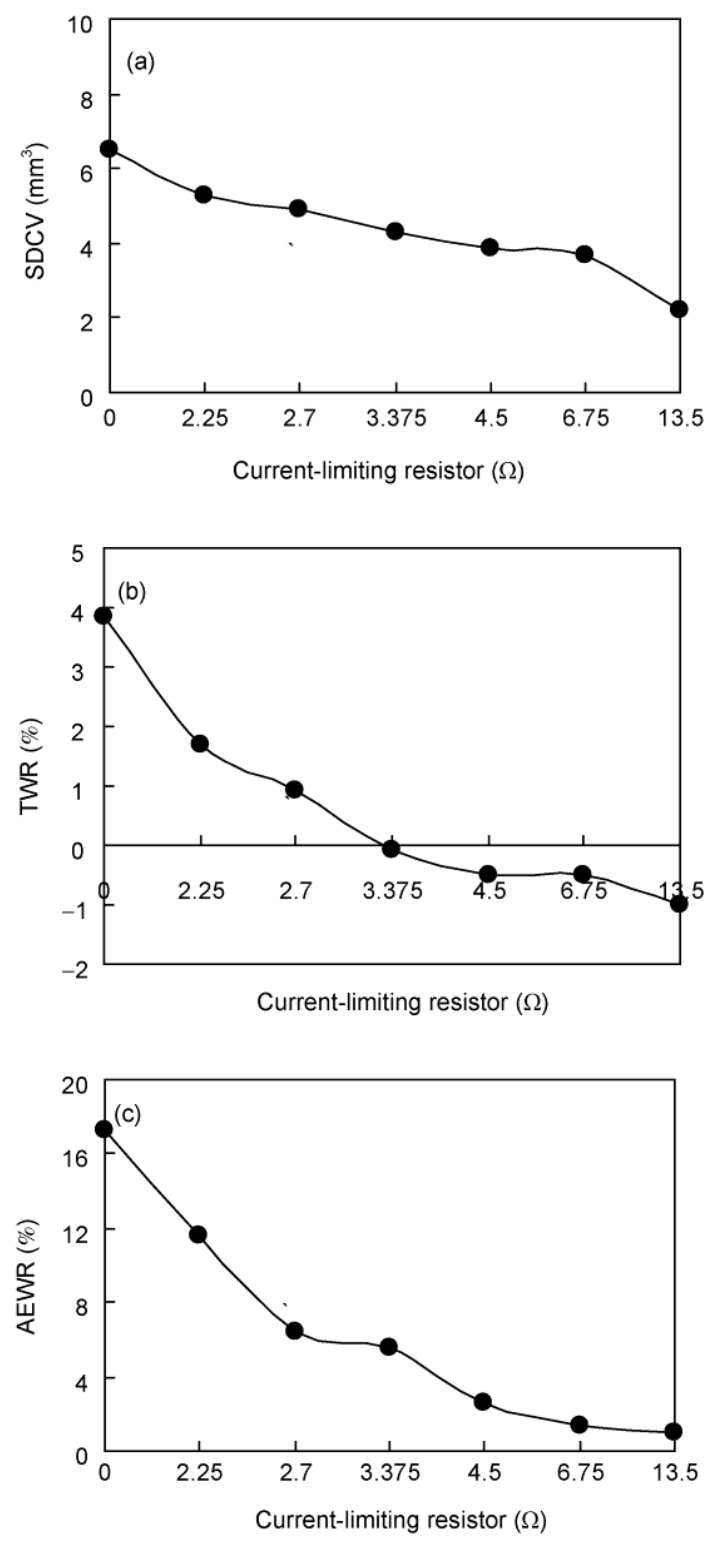

图 6 限流电阻对加工效果的影响

（a) 限流电阻对陶瓷去除量的影响; (b) 限流电阻对工具电极损耗的 影响; (c) 限流电阻对辅助电极损耗的影响

的影响关系. 由图 8 可知, 在其他条件相同的情况 下，工具电极平动时的陶瓷去除量是垂直移动时的 1.3 1.5 倍, 工具电极平动时的工具电极损耗是垂直 移动时的 1.1 5.9 倍, 工具电极垂直移动时的辅助电 极损耗是平动时的 4.9 6.0 倍. 上述现象可解释为: 工具电极垂直移动时, 工件材料主要通过辅助电极 传递的放电能量而去除, 而工具电极平动时, 除了 辅助电极传递放电能量之外, 放电通道直接作用在 

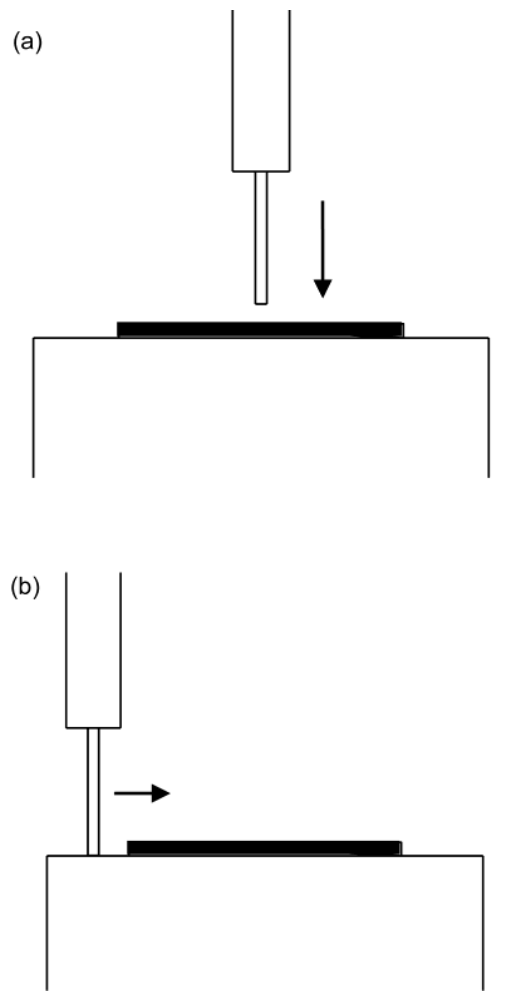

图 7 不同工具电极移动方式示意图

(a) 工具电极垂直移动; (b) 工具电极平行移动

工件表面上, 这增加了对工件材料的去除作用, 因 此陶瓷去除量较高. 工具电极垂直移动时, 由于放 电空间较小, 在工具电极表面容易黏附未能及时抛 出的熔化材料, 减小了工具电极的损耗, 工具电极 平动时, 放电空间较大, 熔化材料不易黏附在工具 电极表面, 因此平动时工具电极损耗较高. 工具电 极垂直移动发生放电时, 放电能量在辅助电极表面 以放电点为中心向周围扩散, 辅助电极表面受热面 积大, 因此损耗较大. 工具电极平动时, 放电点是 作用在辅助电极的厚度方向上, 受热面积小, 因此 损耗较小.

\section{6 工具电极横截面积对加工效果的影响}

图 9 为在其他条件相同的情况下, 得到的工具电 极横截面积与陶瓷去除量、工具电极损耗以及辅助电 极损耗的关系曲线. 由图 9 可以看出, 随着工具电极 横截面积的增加, 陶瓷去除量、工具电极损耗和辅助 电极损耗均减小, 这是因为随着工具电极横截面积 的增加, 放电通道的能量密度和放电爆炸力减小, 陶
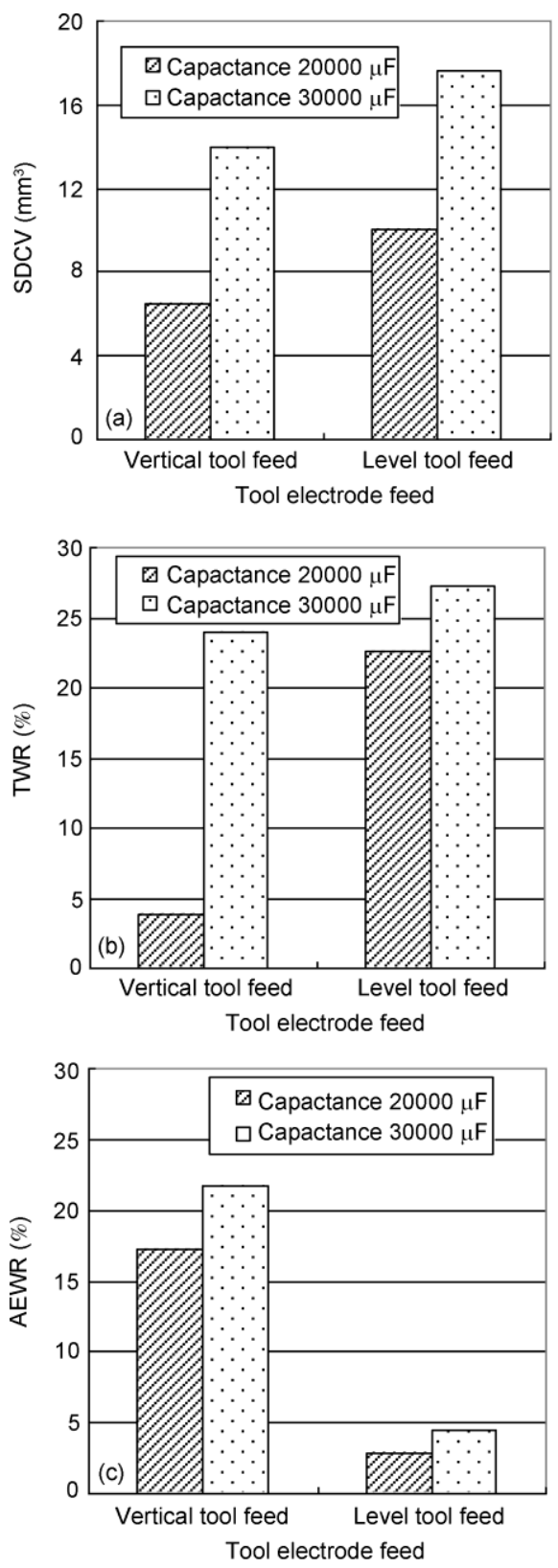

图 8 工具电极移动方式对加工效果的影响

(a) 工具电极移动方式对陶瓷去除量的影响; (b) 工具电极移动方式 对工具电极损耗的影响; (c) 工具电极移动方式对辅助电极损耗的 影响

瓷和电极材料的去除效果减弱. 由图 9 还可以看出, 当工具电极截面积大于 $4 \mathrm{~mm}^{2}$ 时, 工具电极损耗为 负值，这是因为当工具电极截面积大于 $4 \mathrm{~mm}^{2}$ 时， 放电爆炸力较小，放电过程中在工具电极表面黏附 的材料超过了其去除的材料, 因此工具电极损耗为 负值. 

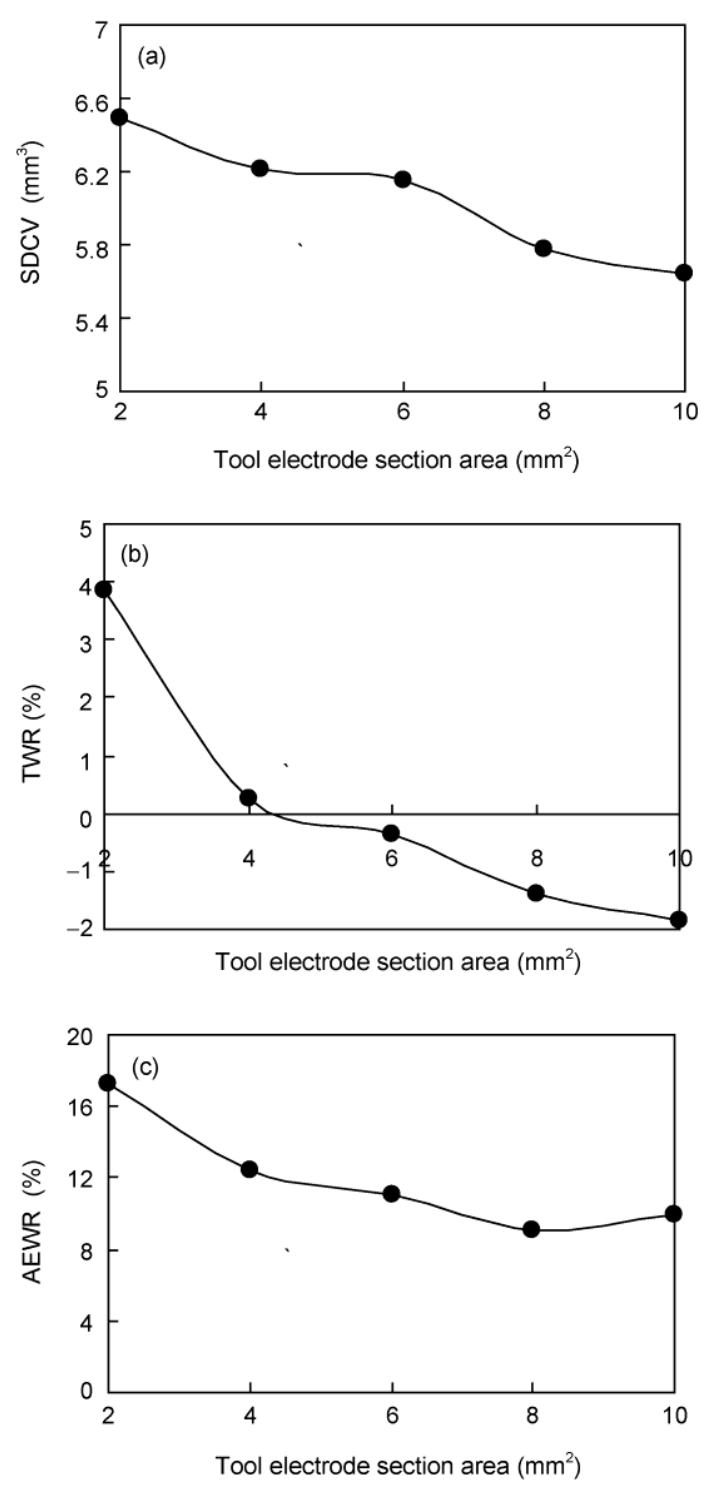

图 9 工具电极横截面积对加工效果的影响

(a) 工具电极横截面积对陶瓷去除量的影响; (b) 工具电极横截面积 对工具电极损耗的影响; (c) 工具电极横截面积对辅助电极损耗的 影响

\section{7 辅助电极厚度对加工效果的影响}

辅助电极厚度对加工效果的影响规律如图 10 所 示, 由图 10 可知, 在其他条件相同的情况下, 随着辅 助电极厚度的增加, 陶瓷去除量、工具电极损耗以及 辅助电极损耗均减小. 上述现象可解释为: 随着辅助 电极厚度的增加, 放电击穿和蚀除铜片所消耗的能 量增加, 传递给陶瓷工件的放电能量减小, 因此陶瓷 去除量减小, 另外随着辅助电极厚度的增加, 可以观
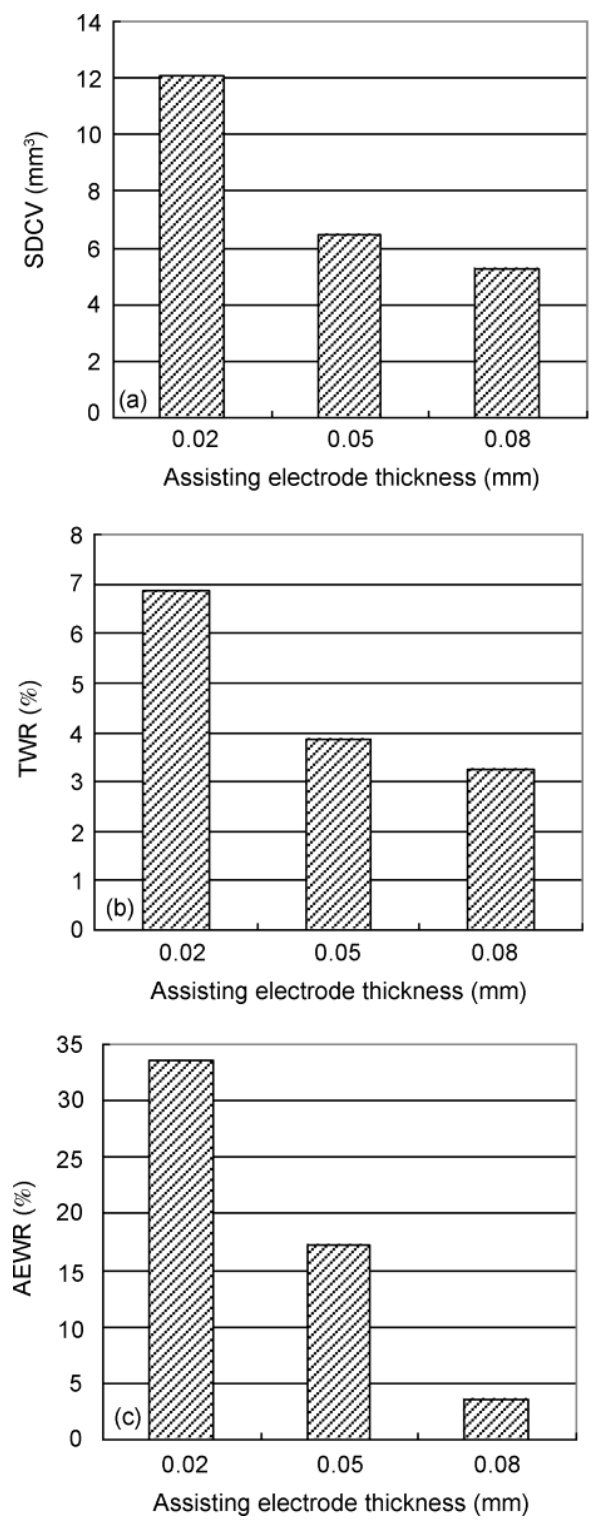

图 10 辅助电极厚度对加工效果的影响

(a) 辅助电极厚度对陶瓷去除量的影响; (b) 辅助电极厚度对工具电 极损耗的影响; (c) 辅助电极厚度对辅助电极损耗的影响

察到放电火花和放电声音变小, 这说明放电爆炸力 减小, 因此熔化的电极材料容易黍附在电极表面使 得工具电极损耗以及辅助电极损耗均减小. 由上述 分析可以看出, 为了得到较高的陶瓷去除量, 需要采 用较薄的辅助电极.

\section{3 非导电工程陶瓷高能量电容单脉冲放电 坑的形貌研究}

不同的单脉冲能量在非导电氧化铝陶瓷表面形 
成的放电坑如图 11 所示. 由图 11 可以看出, 放电坑 表面从中心到四周呈溅射状, 且溅射效应随着单脉 冲能量的增加而增强. 分析认为, 在脉冲放电的极短 时间内能量高度集中在微小区域, 放电通道中心位 置形成的高温、高压使电极以及工件材料迅速熔化, 熔化的材料随着放电通道的扩张向四周溅射. 放电 结束后, 放电通道的温度迅速下降, 涌出的熔融物迅 速凝固, 因而形成溅射状的放电坑表面. 随着单脉冲 能量的增加, 熔化的材料和放电爆炸力增加, 使更多 的熔融材料溅射飞出, 因此材料的溅射效应随着单 脉冲能量的增加而增强.

图 12 为单脉冲放电时不同峰值电压产生的放电 坑底部的 SEM 显微照片, 由图 12 可以看出, 在放电 坑的底部有很多圆形小坑, 且圆形小坑的数量随着 峰值电压的增加而增加. 这种现象可解释为: 在加工 过程中由于采用较高的电压和电容, 单个脉冲的能 量可达数百甚至上千焦耳, 放电能量在工件表面产 生很高的温度和压力, 使得陶瓷材料迅速熔化蒸发. 另外, 由于放电通道中等离子体的振荡, 使得放电通 道发生偏移和波动, 因此在放电坑底部形成多个圆 形小坑. 随着峰值电压的增加, 单个脉冲能量增加, 放电能量密度和放电爆炸力增大, 加剧了放电通道
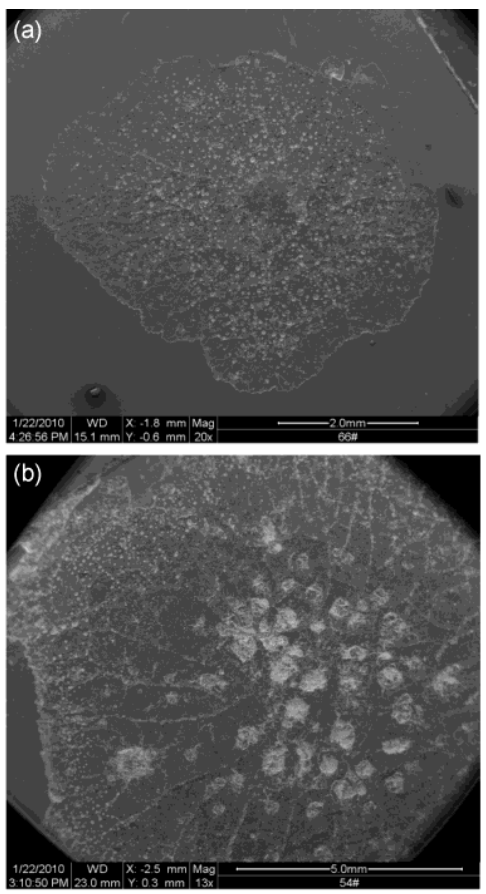

图 11 不同单脉冲能量放电坑表面形貌的 SEM 显微照片 (a) 单脉冲能量为 $225 \mathrm{~J}$; (b) 单脉冲能量为 $1350 \mathrm{~J}$
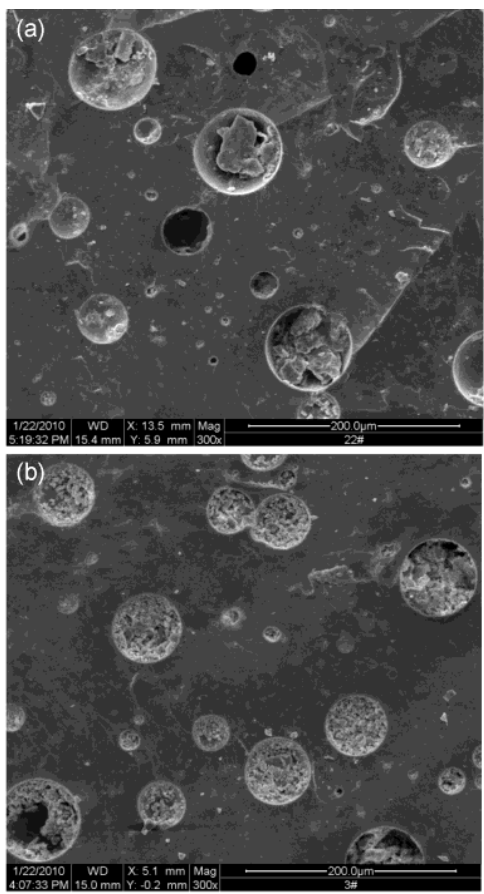

图 12 不同峰值电压产生的放电坑底部的 SEM 显微照片

(a) 峰值电压为 $100 \mathrm{~V}$; (b) 峰值电压为 $300 \mathrm{~V}$

的偏移和波动, 因此圆形小坑的数量增加. 由图 12 还可以看出, 在圆形小坑中有很多颗粒, 且颗粒数量 随着电压的增大而减少. 这是由于熔化的材料不能 被完全抛出, 剩余部分在小坑内冷却形成颗粒, 随着 电压的增加, 单个脉冲能量增加, 放电爆炸力增大, 因此更多的熔化材料被抛出，使坑内颗粒的数量减 少.

图 13 为单脉冲放电时不同电容产生的放电坑边 缘的 SEM 显微照片, 由图 13 可以看出, 在放电坑的 边缘材料以剥落方式去除, 且随着电容的增加剥落 作用增强. 这种现象可解释为: 加工过程中电容储存 的能量瞬时释放到加工间隙中, 由于氧化铝陶瓷高 的硬度和脆性，在工件表面放电点处会产生很高的 温度梯度和热应力. 该热应力很容易超过氧化铝的 抗张强度, 因此使其以剥落方式去除. 随着电容的增 大, 放电能量增加, 在工件表面产生的温度梯度和热 应力变大，因此材料的剥落作用增强.

由上述分析可以得到非导电工程陶瓷高能量电 容单脉冲放电加工的过程：当介质击穿后，放电电流 瞬时增大形成高温放电通道, 大量的能量通过辅助 电极传递给工件, 在工件表面形成很高的温度梯度 

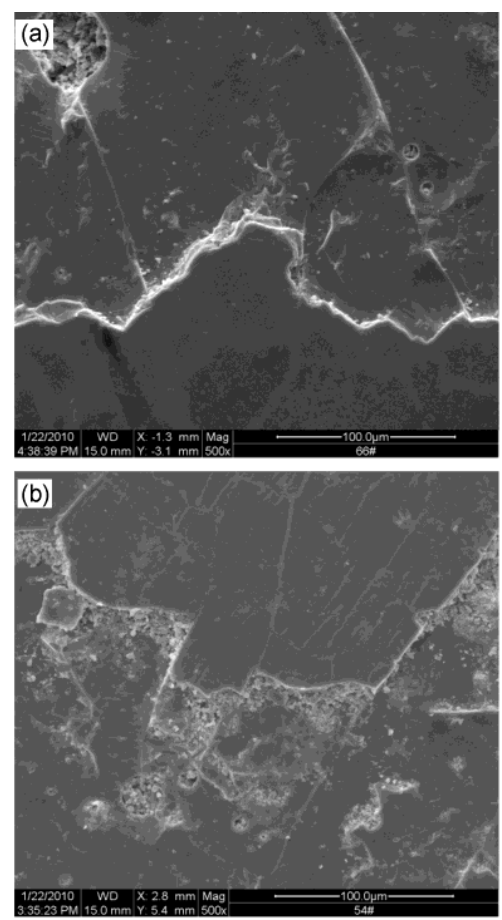

\section{图 13 不同电容产生的放电坑边缘的 SEM 显微照片}

(a) 电容为 $5000 \mu \mathrm{F}$; (b) 电容为 $30000 \mu \mathrm{F}$

和热应力, 该热应力很容易超过非导电工程陶瓷的 抗张强度, 使得陶瓷材料主要通过剥落方式去除, 在 放电通道中心区域部分材料通过熔化蒸发方式去除. 由于熔化的材料随着放电通道的扩张向四周溅射, 使得放电坑表面呈溅射状. 此外, 由于放电通道的偏
移和波动在放电坑底部形成很多圆形小坑

\section{4 结论}

1) 提出了非导电工程陶瓷高能量电容电火花加 工新方法, 并进行了单脉冲放电的试验研究. 结果表 明, 由于在加工过程中采用高电压大电容以及较高 的放电能量, 因此能够得到较高的材料去除效率, 单 个脉冲的陶瓷去除量可达 $17.63 \mathrm{~mm}^{3}$.

2) 在试验设定的参数范围内, 陶瓷去除量、工具 电极损耗以及辅助电极损耗随着峰值电压、电容的增 加而增大, 但随着限流电阻、工具电极横截面积、辅 助电极厚度的增加而减小. 在其他条件不变时, 工具 电极平动时的陶瓷去除量、工具电极损耗以及辅助电 极损耗分别是工具电极垂直移动时的 1.3 1.5 倍、1.1 $\sim 5.9$ 倍、 1/6.0 1/4.9. 在其他条件相同的情况下, 负 极性工具电极加工时的陶瓷去除量、工具电极损耗以 及辅助电极损耗分别是正极性工具电极加工时的 1.1 1.7 倍、 $1 / 4.3 \sim 1 / 3.3 、 1 / 4.6 \sim 1 / 1.8$, 因而工具电极 接电源负极时能得到较好的加工效果.

3) 对非导电工程陶瓷高能量电容单脉冲放电坑 的形貌研究发现, 放电坑表面呈溅射状, 在放电坑底 部有很多圆形小坑, 放电时在工件表面产生极高的温 度梯度和热应力使得陶瓷材料主要以剥落方式去除, 放电通道中心区域部分陶瓷材料以熔化蒸发方式去 除，且材料去除效果随着加工参数的增大而增强.

\section{参考文献}

1 Lorenzo-Martin C, Ajayi O O, Singh D, et al. Friction and wear behavior of zirconia ceramic materials. Ceram Eng Sci Proc, 2009, 29(4): $75-84$

2 Bandyopadhyay W S, Biswas S K, Maiti H S. Nitride \& oxy-nitride ceramics for high temperature and engineering applications. Key Eng Mat, 2009, 395: 193-208

3 罗海辉, 张福成, 王天生. 颗粒强化氧化铝基复合陶瓷断裂特性的预测. 中国科学 $\mathrm{E}$ 辑: 技术科学, 2008, 38(11): 1944-1951

4 Tian X L, Yang J F, Liu C, et al. Research progress of advanced machining technologies for engineering ceramics. Adv Mater Res, 2009, 69-70: $359-363$

5 Guo L, Xie G Z, Li B. Grinding temperature in high speed deep grinding of engineering ceramics. Int J Abras Technol, 2009, 2(3): 245-258

6 Arai S, Wilson S A, Corbett J, et al. Ultra-precision grinding of PZT ceramics-surface integrity control and tooling design. Int J Mach Tools Manuf, 2009, 49(12-13): 998-1007

7 Mehta R C S, Jadoun R S, Kumar P, et al. Application of Taguchi method in the optimization of process parameters for conicity of holes in ultrasonic drilling of engineering ceramics. Ceram Eng Sci Proc, 2008, 28(7): 167-178 
8 Churi N J, Pei Z J, Shorter D C, et al. Rotary ultrasonic machining of dental ceramics. Int J Mach Mach Mater, 2009, 6(3-4): 270-284

9 Samant A N, Dahotre N B. Laser machining of structural ceramics - A review. J Eur Ceram Soc, 2009, 29(6): 969-993

10 Kacar E, Mutlu M, Akman E, et al. Characterization of the drilling alumina ceramic using Nd:YAG pulsed laser. J Mater Process Technol, 2009, 209(4): 2008-2014

11 Guo Y F, Deng G Q, Bai J C, et al. Electrical Discharge Machining (EDM) phenomena of insulating $\mathrm{ZrO}_{2}$ ceramics with assisting electrode. Key Eng Mat, 2008, 375-376: 313-317

12 Liu Y H, Ji R J, Li X P, et al. Effect of machining fluid on the process performance of electric discharge milling of insulating $\mathrm{Al}_{2} \mathrm{O}_{3}$ ceramic Int J Mach Tools Manuf, 2008, 48(9): 1030-1035

13 Yin S H, Ohmori H, Dai Y T, et al. ELID grinding characteristics of glass-ceramic materials. Int J Mach Tools Manuf, 2009, 49(3-4): 333-338

14 Chak S K, Venkateswara $\mathrm{R}$ P. Trepanning of $\mathrm{Al}_{2} \mathrm{O}_{3}$ by electro-chemical discharge machining (ECDM) process using abrasive electrode with pulsed DC supply. Int J Mach Tools Manuf, 2007, 47(14): 2061-2070

15 Liu Y H, Jia Z X, Liu J C. Study on hole machining of nonconducting ceramics by gas-filled electrodischarge and electrochemical compound machining. J Mater Process Technol, 1997, 69(1-3): 198-202

16 Chak S K, Venkateswara $\mathrm{R}$ P. The drilling of $\mathrm{Al}_{2} \mathrm{O}_{3}$ using a pulsed DC supply with a rotary abrasive electrode by the electrochemical discharge process. Int J Adv Manuf Technol, 2008, 39(7-8): 633-641

17 Fukuzawa Y, Mohri N, Tani T. Machining characteristics of insulating ceramics by electrical discharge machine. Ind Ceram, 2001, 21(3): 187-189

18 Muttamara A, Fukuzawa Y, Mohri N, et al. Probability of precision micro-machining of insulating $\mathrm{Si}_{3} \mathrm{~N}_{4}$ ceramics by EDM. J Mater Process Technol, 2003, 140(1-3): 243-247

19 黑松彰雄. 新素材難加工材の MEEC 加工法. ツレ ス技術, 1986, 24(12): 82-88

20 Liu Y H, Ji R J, Li X P, et al. Electric discharge milling of insulating ceramics. Proc Inst Mech Eng Part B-J Eng Manuf, 2008, 222(2): 361-366

21 Liu Y H, Li X P, Ji R J, et al. Effect of technological parameter on the process performance for electric discharge milling of insulating $\mathrm{Al}_{2} \mathrm{O}_{3}$ ceramic. J Mater Process Technol, 2008: 208(1-3): 245-250

22 曹凤国. 电火花加工技术. 北京: 化学工业出版社, 2005. 16-18 